transferred to the new school. The building is divided into two floors, of which the first includes a large waiting hall, lecture theatre (fitted with an epidiascope), a dark room for thirty students, and luncheon rooms. The second floor is provided with a large museum, liberally furnished with models, pictures, and stereoscopic views of external diseases of the eye. There are pathological specimens and microscopical slides are also on exhibit. Attached to the museum is a studio with a dark room. A library and a room for practising operations upon dummy eyes are also provided. The silver key used in formally opening the building had inscribed upon it "In tenebras lucem."

\title{
The Illumination of Mines
}

The interesting account of the discussion on the illumination of mines which we were enabled to publish last month by the kindness of the Illuminating Engineering Society, shed considerable light on what expert opinion agreed in considering the best form of lamp. That opinion was largely in favour of the electric lamp. The discussion was, and naturally so, mainly confined to medical men and representatives of lamp makers, and little was said about the opinions of the user of the lamp, the miner himself. Mr. J. George said that in one district in Scotland the miners have the best oil lamp to go down with for nothing, but they prefer to pay 9d. per week and have the electric lamp. If further corroboration of this statement is needed it may be found in a note in the Electrical Review for April 9th, p. 466, "Electric Lamps in Mines. As a protest against the non-provision of electric lamps in the minewhich they claim give more safety and a better light below ground $-1,400$ men employed at the Tirpentwys Colliery, Pontypool, have given a fortnight's notice to cease work." We are indebted to the courtesy of Mr. L. Gaster, the Hon. Secretary of the Illuminating Engineering Society, for the above reference. Although it must be admitted that the miners are only too ready to strike for any cause at the present time, the above statement would certainly show that they approve of the electric lamp.

\section{Cobalt Glass in Refraction Work}

The use of cobalt glass as an occasional aid in refraction has been known for many years, and is the subject of casual reference in some text-books. It is usually spoken of as being of great scientific interest but of little practical use; but occasionally in dealing with intelligent patients it proves of great service. Its 
value lies mostly in the rapidity with which one can find the axis of astigmatism even of small degrees, and also as a confirmatory test when the full correction has been put up. The principle on which the test is based is the cutting out of all rays between the two extreme ends of the visible spectrum. Not all specimens of cobalt glass do this in a satisfactory manner, but a good cobalt allows only red rays and blue rays to pass through. As the refrangibility of the blue rays is much greater than that of the red rays, they are brought to a focus sooner. In a normal emmetropic eye, where a point of white light placed at distance of 6 metres is focussed on the retina, the red rays will have their focus behind the retina and the blue rays in front of the retina, and the two pencils will intersect in the retina and give a uniformly coloured light with sharp edges. If the eye be myopic a red centre of light will be seen with a blue fringe, and if hypermetropic a blue centre with a red fringe. Hypermetropic astigmatism gives a blue centre with red dots on each side and the inclination of the dots is at right angles to the axis of the astigmatism. In mixed astigmatism the blue extends to a rod with the red on each side and in myopic astigmatism one gets a red centre with blue caps extending from it. The test is only occasionally serviceable, as it is entirely a subjective test, but at times it may save ten or fifteen minutes' work and give a very clear indication as to the nature and degree of error.

\section{ABSTRACTS}

\section{I.-REMEDIES}

(I) Gerrard, Georges (Lille).-On the curability of trachoma by oxidised naphthol-camphor. (De la curabilité du trachome par le naphtol-camphré oxydé). Annal. d'Ocul., December, 1919.

(1) Gérard has elaborated a technique for trachoma which, after three years' use, he recommends very highly in the present article. He has tried other remedies but gets better results, at least in the acute and exuberant trachomas, with oxidised naphthol-camphor, accompanied by iodine and zinc chloride, than with any other. In 1916 he suggested that trachoma was a local manifestation of tubercle, and finding confirmation of the presence of tuberculous lesions in many. of his bad trachoma cases he thought to apply the anti-tuberculous drugs to a disease which he associated with tubercle. With certain precautions, which he has elaborated and illustrated in the present paper, he finds that naphthol-camphor is well tolerated, 